Article

\title{
Reliable 2D Crowdsourced Cadastral Surveys: Case Studies from Greece and Romania
}

\author{
Chryssy Potsiou ${ }^{1, *}$, Cornel Paunescu ${ }^{2}$, Charalabos Ioannidis ${ }^{1}$, Konstantinos Apostolopoulos ${ }^{1}$ \\ and Florin Nache ${ }^{2}$ \\ 1 Lab of Photogrammetry, Department of Topography, School of Rural and Surveying Engineers, National \\ Technical University of Athens, 9 Iroon Polytechniou St., 15780 Athens, Greece; \\ cioannid@survey.ntua.gr (C.I.); kwstastop@gmail.com (K.A.) \\ 2 Faculty of Geology and Geophysics of the University of Bucharest, Strada Traian Vuia 6, 020956 Bucharest, \\ Romania; cornelpaun@gmail.com (C.P.); nacheflorin@yahoo.ro (F.N.) \\ * Correspondence: chryssy.potsiou@gmail.com
}

Received: 6 December 2019; Accepted: 27 January 2020; Published: 1 February 2020

\begin{abstract}
This paper is part of a doctoral dissertation $(\mathrm{PhD})$ research that investigates the development of a procedure for reliable 2D crowdsourced cadastral surveying introducing the use of new Information Technology IT tools and increased citizen participation, supported by m-services. For the development of this procedure, the formal cadastral procedure applied currently in two Europeans countries, Greece and Romania, for their modern nation-wide projects is firstly investigated. The first part of this paper briefly investigates the current stage of progress of those projects in both countries, as well as the specifications and procedures applied for the cadastral surveys, and assesses the level of participation of the right holders and the efficiency of the current procedures. Then, a proposal for a crowdsourced general procedure with increased participation of the right holders in the initial cadastral data collection phase is designed that it may be of value either for the planners of those two projects to improve their projects towards a more fit-for-purpose approach and successfully meet the deadlines timely, or for researchers and planners of other projects with similar nation-wide approaches which also require accurate, assured and authoritative end products. For the assessment of the applicability of the proposal, three case studies are held and tested in urban, rural and suburban areas in both countries, using both a commercial application and an open source one. These crowdsourced surveys are compared to the formal cadastral surveys that have been compiled by cadastral professionals in both countries and the achieved results are assessed and judged as satisfactory in terms of geometric accuracies and the avoidance of gross errors in the location of the parcels. A proposal for future research in order to further improve the proposed procedure is discussed.
\end{abstract}

Keywords: crowdsourcing; Cadastre; land administration; opensource

\section{Introduction}

Cadastre is a major land tool for each country that aims, among other, to improve security of tenure, ensure access to credit for the poor and middle-income households, adopt fair property taxation, and establish a sustainable real estate market that will create a favourable environment for investment and lead to poverty and climate change impact reduction [1]. Greece and Romania are both EU countries that still do not have a complete and updated cadastre for the whole of their territories and are currently running parallel property registration projects which are closely monitored and reviewed by international and local experts [2-7]. This fact increases scientific trust that these two projects are planned (always within the legal, socioeconomic and political framework of each country) 
according to the current international and local experience and according to the required practices for a technically and legally reliable, approach aiming to develop a AAA (Accurate, Assured and Authoritative) [8] cadastre. According to the formal procedure, the technical specifications for the collection of the necessary geospatial and cadastral information are defined by the responsible National Cadastral and Mapping Agencies (NCMAs) and the cadastral surveys are then commissioned to the private sector in both countries through a bid process. Both projects began with a series of pilot participatory projects that have highlighted all the problems and challenges. Right holders are asked to participate and identify and locate the land parcels on orthophotos, declare their rights and submit all relevant documents. Both projects use photogrammetric methods and orthophotos as basemaps to initially collect cadastral information. For the Greek project additional field surveys are conducted only where necessary, as the private surveyors may choose any method they consider sufficient (which is a fit-for-purpose approach), while for the Romanian project cadastral maps are compiled obligatory through field surveys.

The aim of this paper is to study the applied formal cadastral data collection procedures in both countries and to develop a general, more fit-for-purpose model and to test the options of introducing new IT tools and an increased citizen participation to speed up the initial cadastral data collection phase while improving the quality and efficiency of the data collection phase, based on previous research [9-12]. The authors of this research aimed that the proposed general fit-for-purpose method would be flexible, adjustable, and applicable to the particular situation of the current projects to establish reliable, accurate, assured, authoritative, and modern cadastres.

The basic idea is to investigate, design, and test a new procedure in which the initial cadastral data collection phase will be accomplished by increased participation and responsibility of the right holders (usually non-professionals) under the supervision of professionals or with the help of some local volunteers, after short training, using modern and low-cost IT technology such as tablets or smart phones and accurate basemaps, in order to ensure the better location of the land parcels, to avoid gross errors, to speed up the overall compilation time, and minimize additional costs in the case of gross errors in the location of the parcels.

\subsection{The Hellenic Cadastre}

The Hellenic cadastral project was initiated in 1995. It aims to finalize property registration throughout the whole Greek territory $\left(131,957 \mathrm{~km}^{2}\right)$ and achieve a full operation by the end of 2020 . The main objective of the Hellenic cadastral project is to implement a systematic registration in the 5,775 administrative territorial units (441 municipalities and 5382 communities). Its specific objectives are adjusted every six months with the use of intermediate project monitoring milestones. The project is conducted in accordance to the improved technical specifications of 1995, as set by Law 2308/1995 [13]. Indeed, it should be emphasized that these are characteristics of "fit-for-purpose" technical specifications of the final product rather than of the method to be used for its production, as it was wisely foreseen that technology will develop rapidly during the compilation period and therefore the most appropriate methods and tools might change rapidly, and thus surveyors and the Mapping Agency should have the flexibility to adjust without the need for new legislation. The Hellenic NCMA has set the required unified geometric accuracies and the content of the final cadastral products. or urban areas RMSx is $\pm 0.5 \mathrm{~m}$; RMSy is $\pm 0.5 \mathrm{~m}$; and RMSxy is $\pm 0.71 \mathrm{~m}$, while for rural areas the RMSx is $\pm 1.0 \mathrm{~m}$; RMSy is $\pm 1.0 \mathrm{~m}$; and RMSxy is $\pm 1.41 \mathrm{~m}$. The absolute accuracy should be $\leq 0.98 \mathrm{~m}$ for a confidence level of $95 \%$. The geometric compatibility of the shape and location of a land parcel is a buffer along the parcel boundary polygon of $\pm 0.5 \mathrm{~m}$ (for urban areas) and of $\pm 2.0 \mathrm{~m}$ (for rural areas). The geometric compatibility of the area size of a parcel is calculated as following: $\Delta_{E}=\left|E-E_{\Delta}\right| \leq E_{A}$, where $\mathrm{E}$ is the measured value, $\mathrm{E}_{\Delta}$ is the area value as written in the deed, or in a pre-existing survey. $\mathrm{E}_{\mathrm{A}}=\Pi . \alpha$ where $\Pi$ is the perimeter of the parcel and $0.2 \mathrm{~m} \leq \alpha \leq 0.3 \mathrm{~m}$ (for urban areas) and $0.95 \mathrm{~m} \leq \alpha$ $\leq 1.50 \mathrm{~m}$ (for rural areas) [14]. The contractors (private cadastral surveying companies) should meet these requirements with the use of tools and methods of their choice as long as they inform the NCMA. 
NCMA has developed IT system and services to facilitate the project and is responsible for the quality control of the final product. However, this "fit-for-purpose" procedure has faced challenges especially in the initial location of the land parcels by the right holders on the basemaps in rural areas. This has created amazingly long delays and extra costs in the project [9].

\subsection{The Romanian Cadastre}

The Romanian cadastral project was initiated in 1996. It aims to finalize property registration throughout the whole Romanian territory $\left(238,391 \mathrm{~km}^{2}\right)$ and achieve a full operation by the end of 2023. Its aim is to efficiently and transparently supply property titles with quality information to the Romanian right holders and to support the development of the real estate market as well as the governmental and international programmes in the field of land management and cadastre. The main objective of the Romanian cadastral project is to implement a systematic property registration in the 3,181 administrative territorial units (103 municipalities, 217 cities and 2861 communities) [15]. The project is held in accordance to the improved technical specifications of 1996 [16], which provide the legal framework necessary to develop a modern cadastre in compliance with European roots, based on Romania's historical traditions. The Romanian NCMA (ANCPI) provides the contractors (private cadastral companies) with the data necessary for starting the cadastral works and ensures the quality control in order to avoid possible errors. The ANCPI has invested in the development of an IT system that ensures the streamlining of the data registration in short time. This IT infrastructure was developed to support specific work processes, so that ANCPI observes performance standards similar to those of the European Union. The Romanian NCMA has set the required accuracies for boundary determination and for the content of the final cadastral products (for urban areas RMSxy is $\pm 0.4 \mathrm{~m}$, while for the non-build-up areas the RMSxy is $\pm 1.0 \mathrm{~m}$ ).

\section{The Fit-For-Purpose (F-F-P) Approach}

In 2014, the UN has revised the Millennium Development Goals (MDGs) [17] and replaced them with the Sustainable Development Goals (SDGs) [18]. These goals are a universal set of 17 goals and 169 targets that UN member states have to accomplish until 2030 [1]. The need for good land administration is clearly outlined in the Sustainable Development Goals (SDGs). Analysis of the 17 goals shows that land administration systems have an impact on the feasibility of many of these goals [19]. Land and natural resources constitute one of the key factors for achieving several of those goals. For instance, land and its good management is a vital component of Goal 1 on eliminating extreme poverty, Goal 2 on ending hunger, Goal 5 on achieving gender equity, Goal 11 on designing sustainable cities, Goal 15 on life on land, and Goal 16 on peace, justice, and strong institutions [20]; all these by 2030. Therefore, it is conceivable that the existence of well-functioning land administration systems is absolutely essential for the achievement of the purposes of the 2030 global agenda.

For many countries, the traditional cadastral surveying methodology is not efficient enough to meet the global agenda reliably, affordably, and timely. However, recent technological improvements, such as the cloud, UAVs, smart applications, VGI methods, and m-services may enable and enhance the vision for a global property registration by 2030. Cadastral survey usually requires the participation of neighbors, family members, etc. [21]. Moreover, policy discourses on land tenure reform and tenure security have triggered the development of innovative fit-for-purpose tools to record tenure information quickly and affordably [22]. This technological innovation in the field of cadastral mapping may be upgraded to a certain level so that the right holders or some local citizens may undertake some tasks that traditionally are in the responsibility of the national cadastral agency and/or of the professional cadastral surveyors. This activity is usually mentioned as "crowdsourcing" in cadastre and land administration.

Initially the introduction of crowdsourcing technology in the cadastral surveying has aroused a lot of concerns mainly about the achieved data quality and the geometric accuracy of data acquisition [23], as well as about the decreasing role of the surveyor while later on discussions in this field have 
uncovered a great and promising potential for a more "fit-for-purpose" approach $[9,11,12]$ always under the supervision of a professional surveyor. The core principle in designing modern fit-for-purpose land administration systems mainly refers to the need for an appropriate selection by the surveyor, or the mapping agency, of the tools and methods for the data collection and for the design of a system for the purpose of improving the management of land issues within a specific country or region reliably, affordably and timely to meet the SDGs, rather than simply following advanced IT standards and technical specifications regardless of the cost and time required for the compilation of the project [24].

Modern land administration systems design should be based on three fundamental principles: (a) the focus on the purpose and how to design the means to achieve it, (b) the flexibility in designing the means according to existing limitations, and (c) the maintenance and incremental improvement of the system [25].

Although the two cadastral projects in both countries have been continuously revised by local and international experts, both projects have faced serious challenges in meeting their deadlines successfully [2,9]. These two cadastral projects have been selected to be investigated in terms of their methodology, experience gained and challenges as there is always space for further improvement and bridging the gaps. The objective of the $\mathrm{PhD}$ research is to (a) study the formal current cadastral survey procedures followed in both countries; (b) investigate the experience gained by the local and international experts in both countries; (c) examine and test options for further improvement towards a more fit-for-purpose approach; and finally $(\mathrm{d})$ develop, test, and propose a fit-for-purpose general crowdsourced model that is flexible, adjustable, and applicable. The first results of this research are presented in this paper. The model still needs to be further elaborated (in its various individual stages of the procedure) and tested in both countries (maybe in a third one as well) to check its general adjustability and applicability.

\section{Formal Hellenic Cadastral Survey: Main Stages}

Since 1853, the System of Transactions and Mortgages has been operating in Greece. The system had about 396 land registry offices. It is a person-centric, analogue, deed system, that ensures the publicity of the registrations, but it does not guarantee legal security of the registered ownership rights. Legal rights and restrictions are not always delineated on maps. Access to the information of the jurisdiction of each land registry office is possible only through the name of the right holder. Therefore, the Hellenic Cadastral project was initiated in 1995 [26]. The goal of the project is the development of a AAA parcel-based title system.

The overall progress of the project is as following (Figure 1): $\left(1^{\text {st }}\right.$ and $\left.2^{\text {nd }}\right)$ About $29 \%$ of country's property rights have been already registered ( 11,442,000 rights); $\left(3^{\text {rd }}\right)$ Another 62\% $(\sim 24,175,000$ rights) are in the process to be finalized and registered; $\left(4^{\text {th }}\right)$ A bidding process for the remaining $7 \%$ of the country's rights $(2,735,000$ rights $)$ is also in process; and about 776,000 rights $(2.0 \%$ of the country's rights) remain to be registered, concerning mainly pre-existing specific cadastres in Athens and some Greek islands such as the Dodecanese Cadastre (existing Cadastre in Rhodes, Kos and part of Leros Islands).

The formal procedure for the Cadastral Surveys in Greece is as following:

A. Selection of the area to be under cadastral survey; call for bids submission; commissioning to the cadastral surveyors (contractors); opening of temporary local offices for the declaration collection and the cadastral survey; NCMA is responsible for this part.

B. Provision of orthophotos by NCMA for the compilation of the draft cadastral basemaps (1:1000 for urban areas and 1:5000 for rural areas). The compilation of initial cadastral basemaps by the cadastral surveyors is conducted photogrammetrically using all existing information from earlier land reform projects that may have created cadastral information in the area, such as urbanization projects, city plans, urban regeneration projects, land consolidation projects, land expropriation projects, or the definition of the coastal line. Field surveys are made only where necessary. 


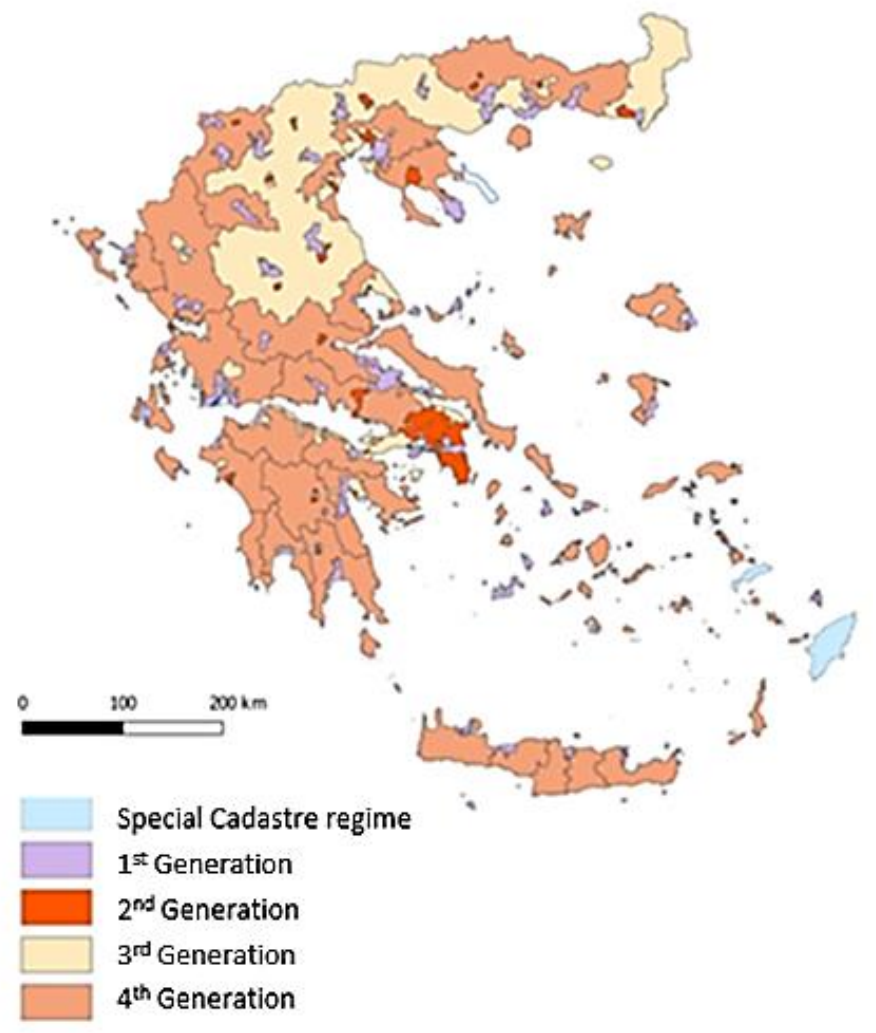

Figure 1. Current Situation in the Hellenic Cadastre [27].

C. Submission of declarations (personal data of the right holder, address, geometrical data of the parcel, types of property rights, information about the deed/title; additional info such as existing field survey or coordinates of the boundary nodes derived by a hand-held GNSS or an abstract of the digital orthophoto with the property boundaries marked on it may also be included) by the right holders and parcel identification on orthophotos. Declarations are submitted either electronically or by visiting the temporary office.

D. Editing by the cadastral surveyor to form the draft cadastral map. Any new changes (subdivisions, transactions, etc.) that may occur until the compilation of the draft cadastral map should be integrated in the digital database by the contractors.

E. Validation of submitted data by lawyers who review their legality and cadastral surveyors. In case of gaps/problems additional field cadastral surveys are compiled or the right holders are asked to bring additional information. The right holder should submit any new changes in the cadastral data (subdivisions, transactions, etc.) that may occur during the cadastral survey period.

F. Publishing of the draft cadastral maps. Extracts of the cadastral maps are mailed to the right holders for their information.

G. Objection submission by the right holders. Two types of errors may occur: the obvious errors and the errors that need thorough examination. Obvious errors, e.g., a spelling mistake in the registration of the proprietor's identity data, or a title, or a land right may be corrected immediately. The remaining objections, mainly refer to corrections of a parcel's geometric data (location, boundaries, shape and size) or to a request for change/removing a right holder from the cadastral tables. Those objections should be examined by an independent administrative committee which consists of three members, two of which are members of the bar association and the other one is a cadastral surveyor.

$\mathrm{H}$. The cadastral data are corrected and the final cadastral tables and maps are formed. These registrations are then called Initial Registrations and they constitute the first/initial registration in the Hellenic Cadastre. 
I. The temporary office for the cadastral survey is then closed and the existing Land Registry Office in the area is replaced by a permanent Cadastral Office.

A flow chart of the procedure is given below (Figure 2).

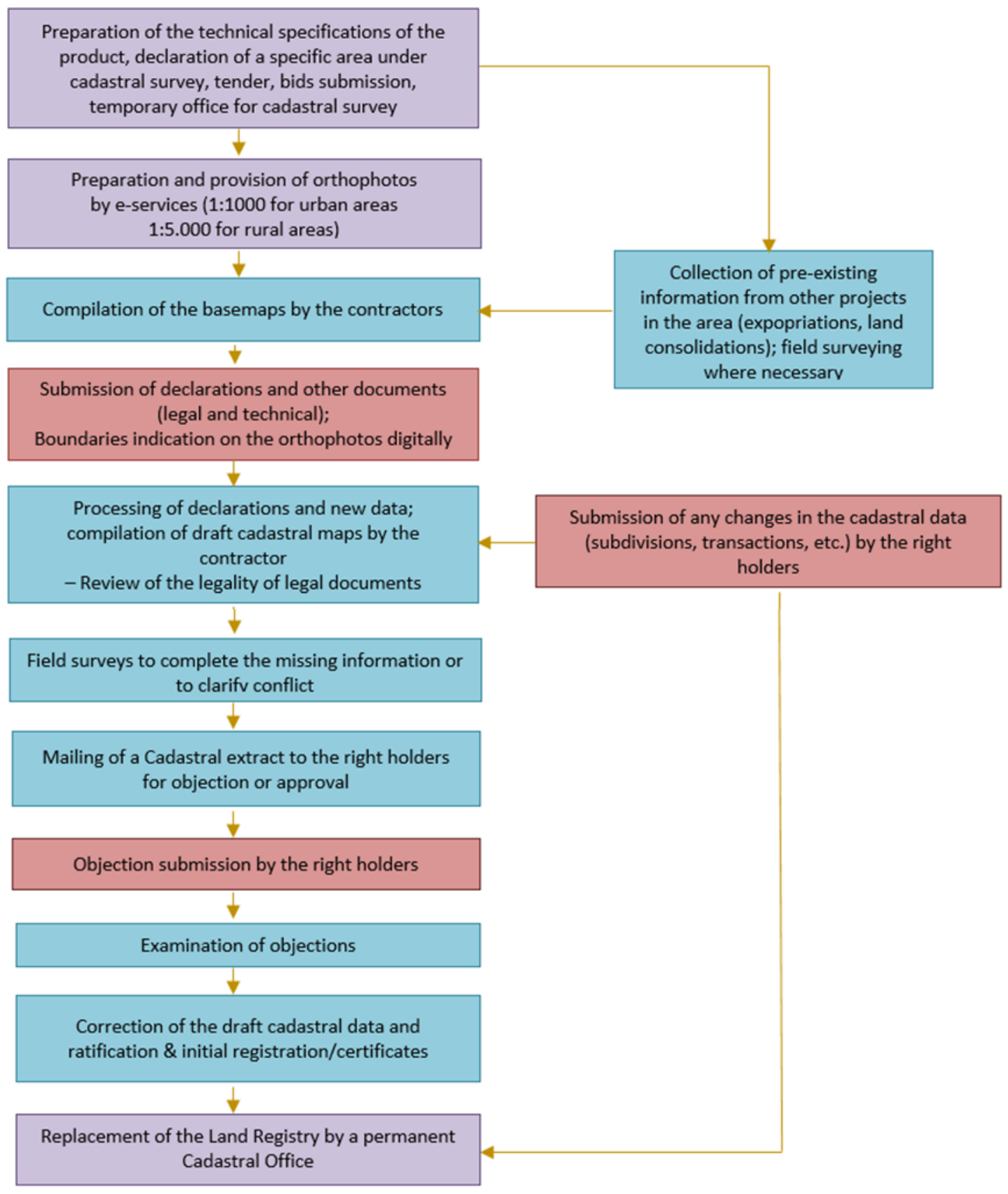

Figure 2. Main stages of the official procedure of the Hellenic Cadastre Survey (stages in purple color depict NCMA actions; stages in blue color depict cadastral surveyors' actions; stages in pink color depict right holders' actions).

\section{Formal Romanian Cadastral Survey: Main Stages}

The first land registrations were held in the regions of Wallachia and Moldavia, between 1831 and 1832. In the regions of Transylvania, Banat and Bucovina, the cadastral works began during the Austro-Hungarian Empire (1870). By the Second World War in Romania, the Land Book system existed in the regions Transylvania, Banat, and Bucovina, and the deed system existed in the rest of the country. 
During communism (1947-1989), private ownership of land was demolished. In 1955, a new cadastral system was implemented to support agricultural land re-parcelling during the collectivization of agriculture. After the fall of communism, the Land Property Law no. 18/1991 has been introduced in order to ensure that the confiscated lands will be returned to their initial owners. Five years later the Law of Cadastre and Land Registration (Law 7/1996) provided the possibilities to develop a modern title registration system and also founded the National Office of Cadastre, Geodesy and Cartography, which became, in 2004, the National Agency for Cadastre and Land Registration (ANCPI - NACLR) [28], the organization responsible for the management of systematic cadastral surveying projects in Romania.

Currently, almost $25 \%$ of Romanian properties are registered as shown in Figure 3. Concerning the remaining $75 \%$ (approximately $30,000,000$ properties), according to a very optimistic estimation by ANCPI, will be registered by 2023. The main challenge of the Romanian cadastral project is related to legal issues and especially the required thorough legal investigation/validation of the submitted documents. This issue causes insecurity in terms of financial sustainability of the project, as this was not planned like that from the beginning [29].

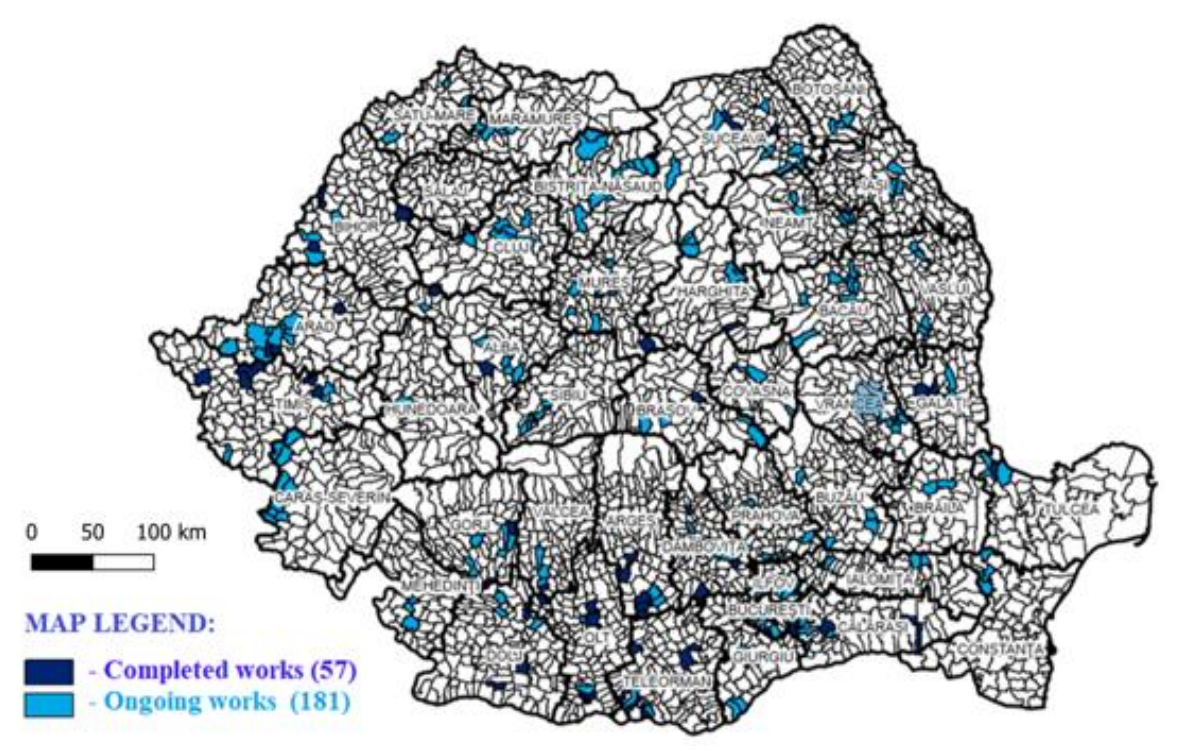

Figure 3. Current Situation in the Romanian General Cadastre.

The formal procedure of the systematic cadastral registration in Romania is as following and is shown in Figure 4:

A. Declaration of a specific administrative territorial unit under cadastral survey; call for bids submission; commissioning to the private cadastral surveyor companies (contractors);

B. Provision of orthophotos by ANCPI to the cadastral surveyors for the compilation of the draft cadastral basemaps. The compilation of draft cadastral basemaps is conducted using and integrating all existing data from the Cadastral Office, from the Town Hall or from other public institutes. Organization and realization of the advertising campaign, at country wide and local level, with the aim of informing the right holders about the start of systematic registration and their benefits, rights and obligations.

C. Compilation of cadastral field surveys (parcel location on orthophotos by the right holders, submission of declarations with the property rights and right holders' data, boundaries and buildings footprint field measurements, processing of declarations and new data by the contractors, as well as validation of the legality of right holders' legal documents). The geometrical data obligatorily result from the field surveys; the contractor has to measure all the properties that can be identified in the field. 


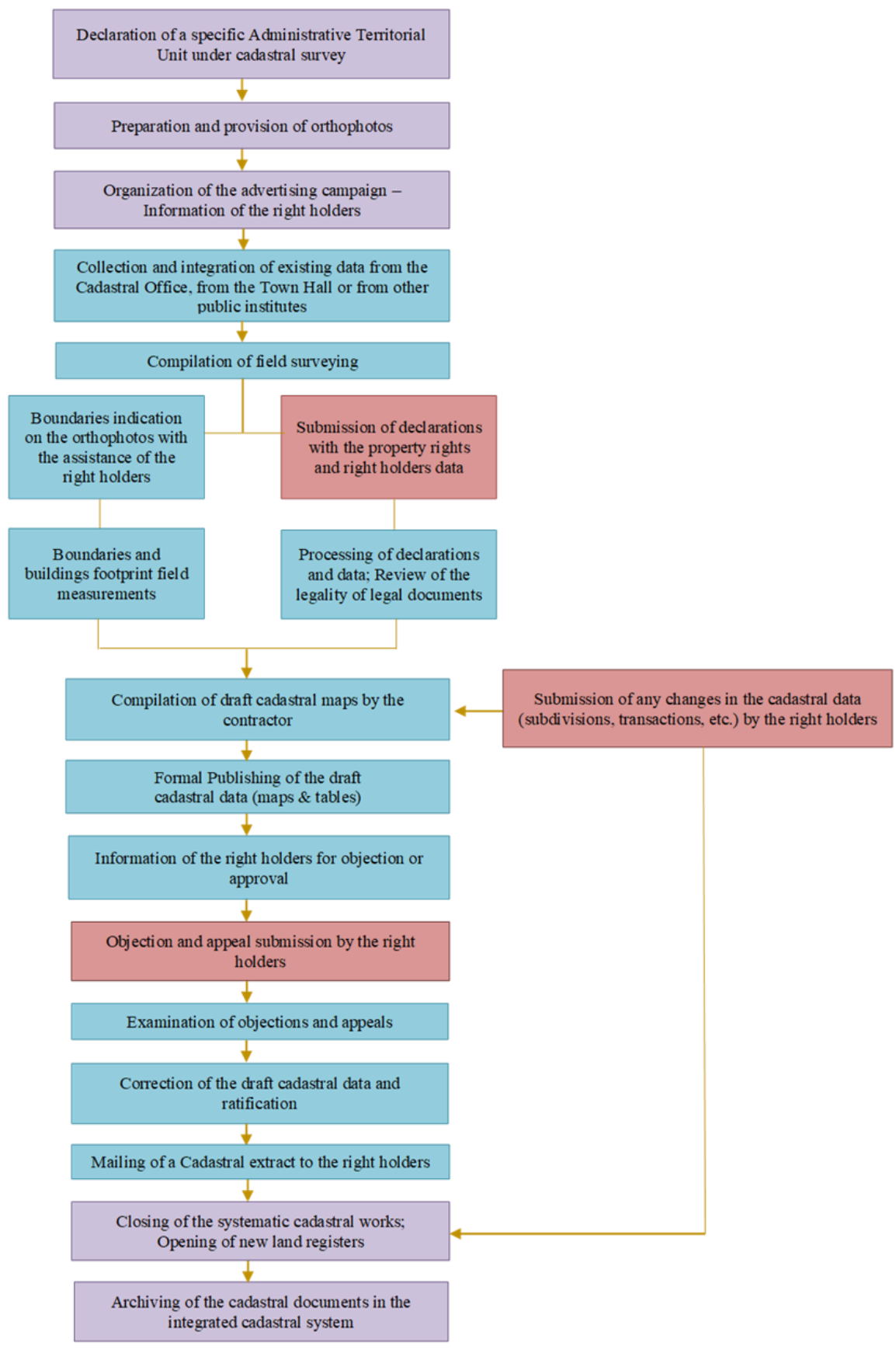

Figure 4. Main stages of the Romanian Cadastre Survey (stages in purple color depict state actions; stages in blue color depict contractors' actions stages in pink color depict right holders' actions).

D. The collected information, is edited by the cadastral surveyor to form the technical cadastral documentation and the draft cadastral map of the administrative area under cadastral survey. Any new changes (subdivisions, transactions, etc.) that may occur until the compilation of the draft cadastral map should reported and integrated in the digital database by the contractors.

E. Formal publishing of the draft cadastral data (maps \& tables) at the ANCPI's offices for a two-month period and information of the right holders.

F. Objection and appeal submission by the right holders. Objections should be examined by an independent three-member administrative committee, of which one member is from ANCPI, another one is a cadastral surveyor, and the last one is from the city hall. 
G. Correction of the cadastral data and update of the technical cadastral documentation according to the results of the examination of objections and the final cadastral tables and maps are formed.

$\mathrm{H}$. Mailing, under the terms of the Law, of a land book extract and an extract of the new cadastral plan to the right holders.

I. Closing of the systematic cadastral works, as well as of the old cadastral and land registry records and opening of new land book registers.

J. Archiving of the cadastral documents in the integrated system of cadastre and land book.

\section{Proposed Model for A New F-F-P Procedure}

Based on the above reports from both countries, a new procedure that may support a more fit-for-purpose approach on the compilation of $2 \mathrm{D}$ crowdsourced reliable cadastral surveying is proposed. Similarities and differences of the formal and the new procedure are highlighted in the next chapter. This new procedure also includes the development and use of (a) a mobile application (for smartphones or tablets) with accurate basemaps, to be used by the right holders and team leaders and (b) a video guide that provides a tutorial for its usage. The application may be either a low-cost commercial one or an open source, or a combination of both. This modern approach is planned to achieve high accuracy of the final product using crowdsourcing technology, and it may be applicable for many countries or modified appropriately in order to become even more affordable and more fit-for-purpose according to the local situation, by using less accurate basemaps such as OpenStreetMap or airphotos, etc. Naturally, the accuracy of the final product will vary accordingly. The procedure should be accompanied by technical specifications of the final product that will allow the choice of the most fit-for-purpose method and basemaps (e.g., crowdsourcing and photogrammetric measurements versus field surveying-when possible, or a combination of them according to the local situation).

\subsection{Main phases of the Proposed New Procedure}

The proposed procedure is presented below (Figure 5).

Preparatory Phase:

The preparatory phase is similar to the stages A, B of the formal cadastral procedures of Greece and Romania. If the NCMA cannot afford the preparation and provision of new LSO and VLSO for the whole territory, an old orthophoto may be of value, while private surveyors may use UAVs to provide recent orthophotos in areas that have had significant development since the acquisition time of the old orthophoto.

Phases 1 and 2 have been totally changed in the new procedure and are described as following:

Phase 1: Compilation of crowdsourced draft 2D cadastral maps. Declaration of rights.

In this phase, all right holders in the area under survey will be asked to digitize the parcel boundaries they have rights to, and submit those together with all the required documents declaring their rights through the Internet. As always, in the cadastral surveying process, community involvement is the basis for success. The right holders should be enabled to use the Internet and their mobile devices, such as smart phones or tablets, for the purpose of the data collection for the initial cadastral registration. Web applications and mobile applications like those used and developed for this research should be created by NCMA in order to facilitate the procedure [12]. Demonstration videos and detailed instructions on how to use both applications must be provided by the contractors or the NCMA.

Digitization of property boundaries and submission of the supporting documents and additional information will be done through a mobile application. As basemap for the digitization of properties, the recent orthophoto with the additional pre-existing cadastral information should be used. Contractors should include any existing cadastral information derived from administrative acts, city-planning projects, urban regeneration projects, land expropriation projects or projects for the definition of the coastal line, as such projects usually create AAA cadastral data of high geometric accuracy. In case the NCMA cannot provide a recent orthophoto of the area, unmanned aerial vehicles may be used by the contractors to obtain high resolution orthophotos. 


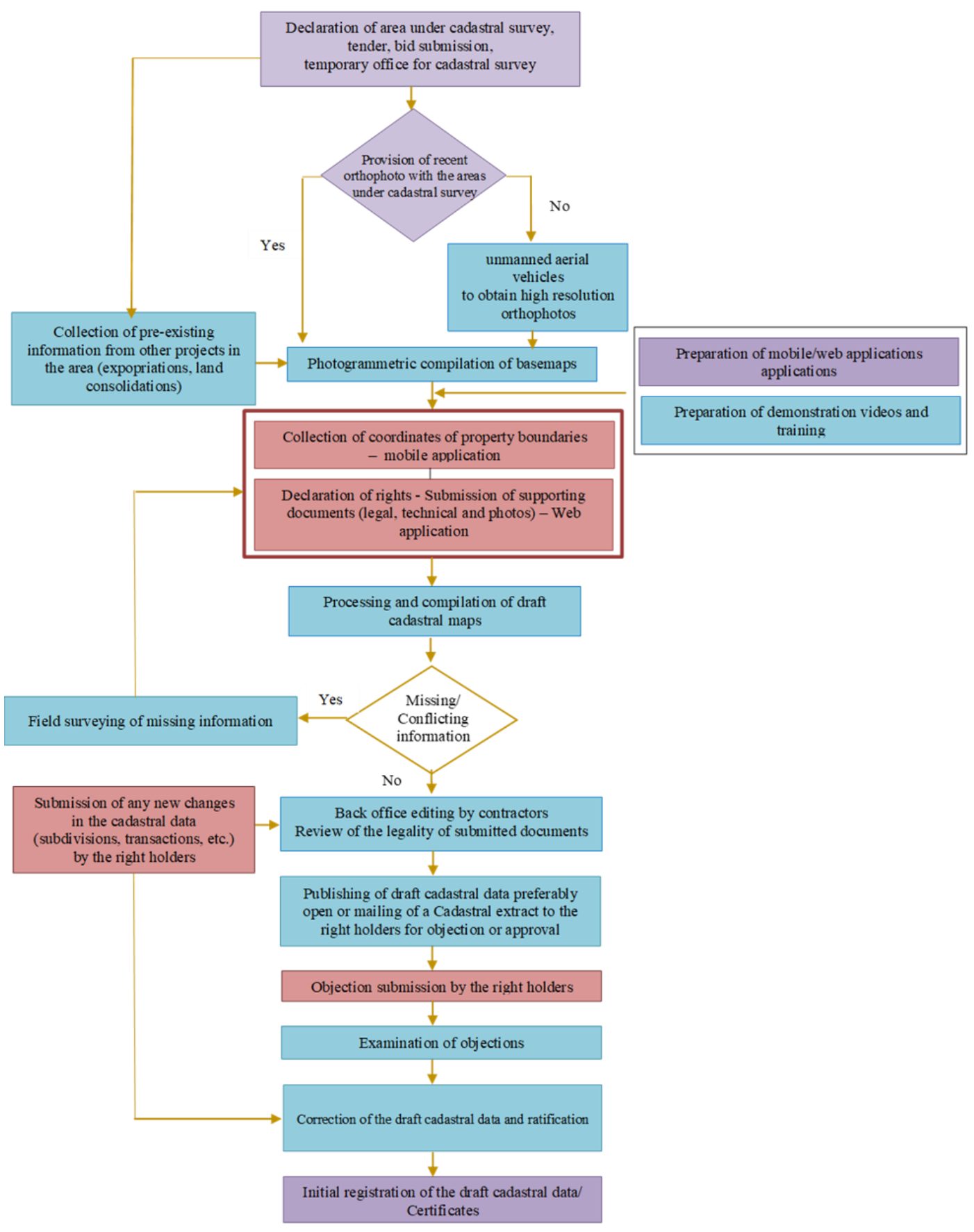

Figure 5. Main stages of the proposed procedure (stages in purple color depict state agency actions; stages in blue color depict contractors' actions; stages in pink color depict right holders' actions).

Right holders may either 'visit' the property on site and delineate the parcel boundaries on the basemap, by digitizing the parcel polygon, or if they can recognize their parcel on the orthophoto, they may digitize the boundaries from a distance. Recent work in this field has shown that the boundaries that could be visible on the basemap and were digitized using smart phones had similar geometric accuracies with those produced by the formal surveying procedures, while invisible on the basemap parcel boundaries that have been digitized using the GNSS of the smartphone had much lower geometric accuracies [12]. 
In difficult cases, for example if some parcel boundaries are not shown or clearly recognized on the orthophoto, or if there is no auxiliary evidence for the recognition of the property boundaries on the basemap (e.g., survey diagram), there are several options to identify them, such as with an accuracy of a few meters by using the smart phone GNSS device, or owners may also walk the perimeters of their land parcels, using a GNSS antennae. Esri's Collector App for example uses a mobile Bluetooth connection to connect with the Trimble R2GPS device. The R2 has a "quality antenna" for the reception of weak GNSS signals and the reception of the required correction signals. This configuration provides, theoretically, sub-meter accuracy for the observed points [30]. Another option is of course to declare difficulty and leave the job to the contractor, to be completed by traditional field surveying.

Usually, each part of a parcel boundary may be digitized several times by the owners of the neighboring parcels. This normally increases the final digitization accuracy. If the discrepancies of the measurements are within the technical specifications, then the mean measurement is selected by the contractors during the editing of the data.

In cases where neighbors do not agree exactly where the border between them is, this issue is dealt by the contractors after checking the submitted documents. State-owned or municipal land parcels should also be registered in a similar way.

Furthermore, the right holder is asked to upload any other evidence confirming the declaration of the property boundaries. Such evidence may include any existing private professional survey diagram of the parcel. Such data will be used by the contractor at a later stage of back-office editing the collected data. Right holders should also upload a statement of their personal data along with the deeds or other legal information, necessary to prove the declared rights. These actions will be performed through a NCMA's web application.

If the right holder is unable to use any of the applications he/she may request assistance. A trained team leader/volunteer/student who may manage the applications, or even a local private surveyor could be used in order to support the right holder.

By the end of phase 1, NCMA will have a draft cadastral map. In addition, a clear view of the types and size of problems will appear; for example, parcels with conflict claimed by many right holders, or a number of non-claimed parcels, etc. The number of undeclared/non-claimed parcels is crucial for this type of participatory process and additional research needs to be compiled on how to activate right holders to participate in such a project [10]. There could be many reasons for this (e.g., the registration fees are high; there is a fear that property taxes will be applied; there is ignorance about the value of the cadaster and property registration, etc).

Phase 2: Back office editing by contractors

Contractors selected through a bid procedure, will receive the collected data from phase 1 and will be asked to create a unified database. Additionally, contractors will validate the legality of the documents that have been sent by the right holders, check the geometrical compatibility of the spatial database and check for gaps in the collected data. Right holders may be contacted, if necessary, in order to clarify some issues. In case of missing information, the team leaders and/ or the right holders will be asked to collect and submit on-site information, or the surveyor/contractor will take care of that issue. If there is a discrepancy between the measured area size and the one written on a deed larger than what is prescribed at the technical specifications the contractors should try to solve the problem- if possible (if not, they just keep the new measurements).

By the end of phase 2, NCMA will receive the draft cadastral maps and tables that will be used for the publishing of the property rights. The NCMA will commission a new task to an independent private company to do the quality control of the geometric accuracy of the received cadastral maps before accepting and publishing those. The quality control will be done sporadically by field surveying of point coordinates which will be then compared to the coordinates of the parcel boundaries of the draft cadastral map.

Phase 3: Formal publishing of the draft cadastral data. 
This phase remains similar to the formal procedures of Greece and Romania, but some improvements are suggested.

Publishing may be done according to the formal procedures of Greece and Romania (stages E and F of previous chapters) either by mailing the data of interest to each right holder separately, although an open publishing is much preferable for transparency issues and a better and faster correction of errors.

Phase 4: Objections - Initial registration

This phase has been changed for the new procedure and is described as following:

Right holders may object and ask to correct any data they have evidence to (e.g., if the area size of a parcel is shown smaller than what is written on a deed and the difference is larger than what the technical specifications prescribe). In such cases a local professional field survey is done and the final result is registered. A weakness that may appear at the objection procedure (as derived from experience in Greece) is that it may take a long time for the committees to finish their work, especially if many objections are submitted for each municipality. A proposed approach may be to sustain only the properties that need a further judgment and the properties that have no objections to be finalized and passed to operations, while the others could wait for further judgment [31]. This approach will need more effort in operations, because they should distinguish the status of each parcel.

Phase 5: Initial registration of draft cadastral data

This stage of the proposed methodology is similar to the final stages of the two official procedures (J of Greece and H,I, and J of Romania.)

\subsection{Video Guide}

For the implementation of the proposed procedure, a video guide has been established that sets out in detail the operation and usage of the above applications. The creation of this video guide was deemed necessary as the right holders are asked to use a combination of applications in order to participate successfully in the land registration process.

In this video guide (Figure 6), Esri's Collector for ArcGIS (a cross-platform mobile data capture application) and MapIT GIS (opensource collector application developed by the authors) are described. Information is provided on how to be installed from Android and IOS markets and on how to use all of the menus. More specifically, the video guide includes the following information:

- In which phase of the land registration process right holders will be involved

- What IT facilities right holders should have in order to participate (e.g., either smartphone or tablet with internet connection preferably)

- Detailed description of the application (menus, specifications etc.)

- Details on what types of data can be recorded (e.g., boundaries, taken photos of the deeds, photos of the parcels).

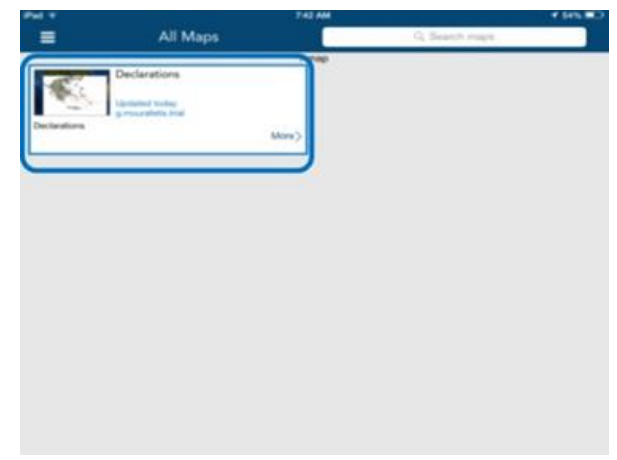

(a)

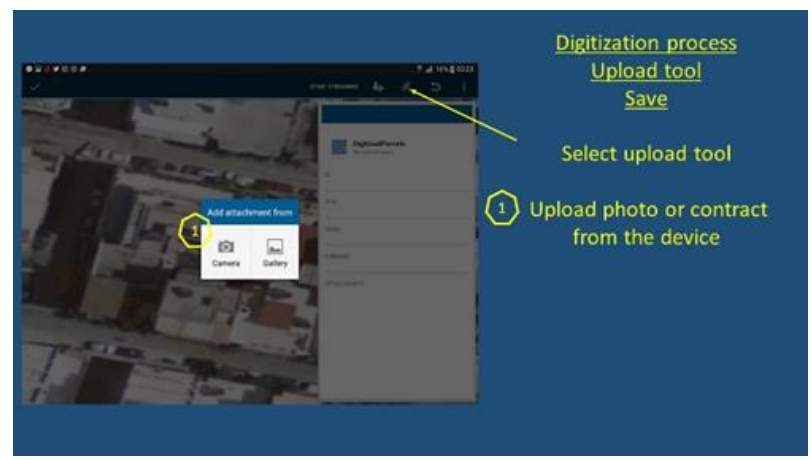

(b)

Figure 6. Indicative screenshots of the applications' video guide. (a): Basemap Selection; (b) Digitization process - Photo upload tool. 


\section{Case Studies}

Three pilot studies to test the achieved geometric accuracy of the proposed procedure were held in both countries, one in Greece and two in Romania. These case studies may also be used as examples of how to apply the proposed methodology for 2D reliable crowdsourced cadastral surveys.

The pilot case study that was conducted in Greece has been held in Gounaris village in the Municipality of Sparta and the pilot case studies that were conducted in Romania have been held in the built-up area of Ciugud village in Alba County and in Caracal city, Olt County.

The application that was used in Greece's case study ESRI's Collector for ArcGIS [32] and the application that was used in Romania's case studies is MapIT GIS application which is opensource.

During these case studies, the volunteers/right holders under the supervision and guidance of a team leader (local citizen who has been informed and trained by a cadastral surveyor about the cadastral procedures and applications) collected cadastral parcel boundaries, building footprints and cadastral descriptive information such as property rights, right holders data, and parcel and building photos. Following the completion of the field procedures a comparison between the crowdsourced cadastral map and the official cadastral map has been conducted.

Comparing the results of the three case studies that were held and tested in urban, rural and suburban areas in Greece and Romania for the assessment of the proposal, a series of useful conclusions are derived.

The crowdsourced cadastral diagrams are within the accuracy tolerance of the NCMAs' official specifications. The costs and time for data collection is reduced radically as compared to the traditional procedure, but the most important is the fact that there are no obvious errors or gross errors or gaps identified in the results of all case studies.

The established video guide was proved very useful and enhanced the crowdsourced cadastral procedure. The right holders were informed about the installation, usage, operation and application's capabilities and were trained to identify their parcel boundaries, with the usage of smartphone's or tablet's GNSS, using NCMA's orthophotos and to add right holder's identity data and upload photos or the scanned deed. Moreover, in the Romanian case studies, the volunteers/ right holders have identified and digitized not only the parcel boundaries but also the building footprints.

\subsection{Case study in Greece}

This case study was held at Gounaris village, which is close to the city of Sparta in the Prefecture of Lakonia, Greece. Gounaris village has a population of 186 inhabitants according to the census of 2011 and its inhabitants are engaged in agriculture and especially the cultivation of citrus, vines and olive trees.

The established video guide has been used in order to inform the right holders about the installation, usage, operation and capabilities of ESRI'S Collector for ArcGIS application. Specifically, they have been trained to identify their parcel boundaries, with the usage of smartphone's or tablet's GNSS, using NCMA's orthophotos (LSO) provided by NCMA produced in 2001 as a basemap, to add right holder's identity data and upload photos or the scanned deeds.

For this case study, a team consisting of 27 volunteers/right holders was composed. About 114 land parcels have been digitized which are the majority of the village land parcels (Figure 7). The case study lasted $15 \mathrm{~h}$ in total. Specifically, it was conducted in three consequent days of five hours daily.

The tablet's GNSS had good signal and was used only for rough positioning with an accuracy of 1-3 m, which was then improved manually by moving the cursor on the NCMA's basemap using the proper zoom. However, it was not possible to distinguish and collect directly from the orthophoto all the property boundaries. In the simplest cases where the boundaries are fixed in the field (e.g., when the boundaries are identical with the parcel hedge) but are not clearly recognized on the orthophoto, the use of the Measure tool of Collector for ArcGIS is needed. 


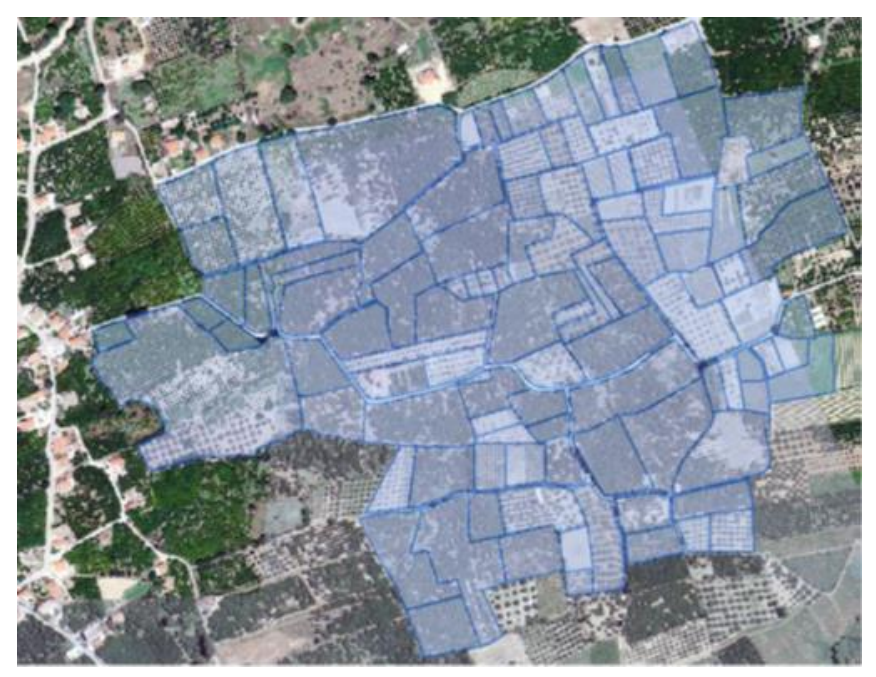

Figure 7. Digitized polygons in Gounaris village using the proposed procedure.

For the registration of the properties, the GNSS of the volunteers' smartphone was used, that had good signal (due to the antenna network in the area) with a positioning accuracy of 1-3 $\mathrm{m}$. In the cases that was not possible to distinguish and collect directly from the orthophoto all the property boundaries but are not clearly recognized on the orthophoto (e.g., cases in which the boundaries are fixed in the field or the boundaries are identical with the building facade) the Measure tool of Collector for ArcGIS was used. These facades were measured using a tape and the measured distance was transferred to the environment of Collector for ArcGIS.

Following the completion of the field procedures, the polygons that have been digitized by the volunteers, have been imported to the application via ArcGIS for Server.

The results were exported by the cloud server of ArcGIS Online and the draft crowdsourced cadastral map was generated. Specifically, in the developed application a map having two basemaps, one from ESRI and one WMS layer from NCMA were created in ArcGIS Online. On top of the basemap, a layer which was created in ArcGIS Desktop was added. On this layer, the citizens have digitized their properties. This information was made publicly available and released in the cloud server of ArcGIS Online.

To check the results derived from the proposed crowdsourced procedure, an official cadastral map of the area was used as reference data (Figure 8a). In order to compare the results of the two datasets, the deviation of the nodes of the crowdsourced cadastral diagrams have been determined. This determination has been done based on the NCMAs specifications geometric compatibility of the shape and location of a cadastral land parcel.

Moreover, the comparison results identified only five obvious errors. Specifically, the land parcels that were identified with obvious errors are the land parcels no 19, 20, 23, 25, and 43.

Land parcels no 19 and 20 are separated in a different way (Figure 8b).

The recorded boundary between parcel no 23 and parcel 25 is different (Figure 8b).

The land parcel no 43, is presented as two land parcels, which is probably a recording error of the formal Cadastral procedure (Figure 9a).

Based on the official specifications it has been determined that 17 land parcels out of the remaining 109 are not within the accuracy tolerance; this number represents $15.5 \%$ of the crowdsourced digitized diagrams. These 17 plots are shown in Figure $9 b$ in light blue. The average accuracy deviation of the boundaries of the land parcels is $\pm 0.55 \mathrm{~m}$ and the maximum deviation is $\pm 1.8 \mathrm{~m}$ which is within the limits of the Hellenic NCMA's technical specifications (RMSxy for urban areas is $\pm 0.71 \mathrm{~m}$ and RMSxy for rural $\pm 1.41 \mathrm{~m}$ areas). 


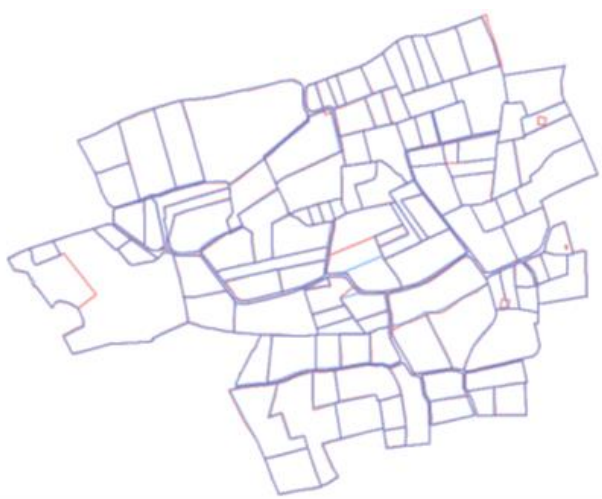

(a)

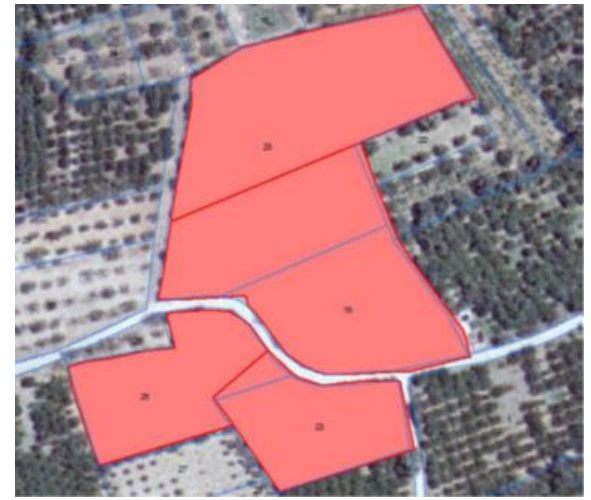

(b)

Figure 8. (a) Comparison of the recorded boundaries using the proposed procedure (in blue) with those obtained from the official Cadastral Maps (in red). (b) Obvious errors in parcel boundaries Different recorded property boundaries.

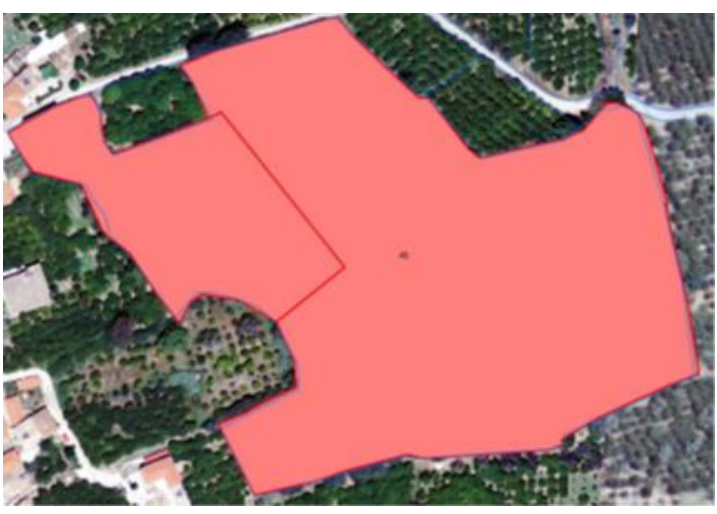

(a)

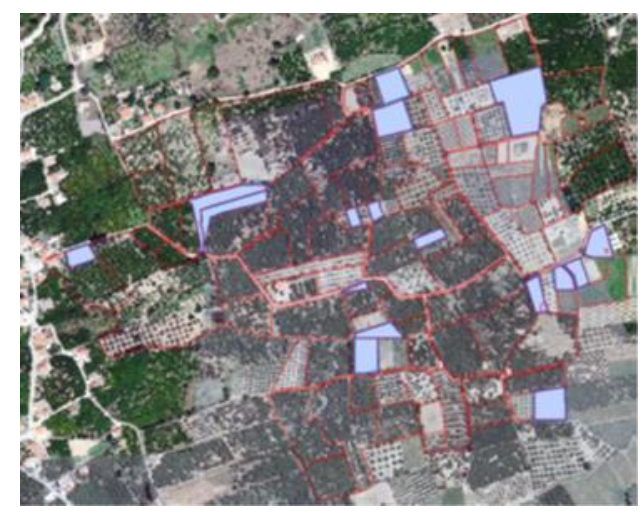

(b)

Figure 9. (a) Obvious errors in parcel boundaries - The land parcel is presented as two land parcels. (b) Land parcels that are not within the value of the "acceptable tolerance" area.

\subsection{Case Study in Romania}

Two study areas were held in Romania, the first one is the build-up area of Ciugud village, Alba County and the second one is a part of the city Caracal, Olt County. These case studies present the benefits of applying this modern techniques and the citizens' participation in the cadastral surveying.

The build-up area of Ciugud covers a $0.6 \mathrm{~km}^{2}$ of plain terrain and the test zone in Caracal is located in the central part of the city and it covers a $0.9 \mathrm{~km}^{2}$ of plain terrain. To gather the cadastral data, for both zones, an opensource collector was developed using the MapIT application. For the development of the cadastral data collector, it was necessary to define the property's boundaries and building attributes (Figure 10) and to create new layers for them. Moreover, unmanned aerial systems have been used to produce the latest and good quality orthophotos instead of large format aerophotogrammetric camera image systems in order to reduce costs and data collection times $[33,34]$ 


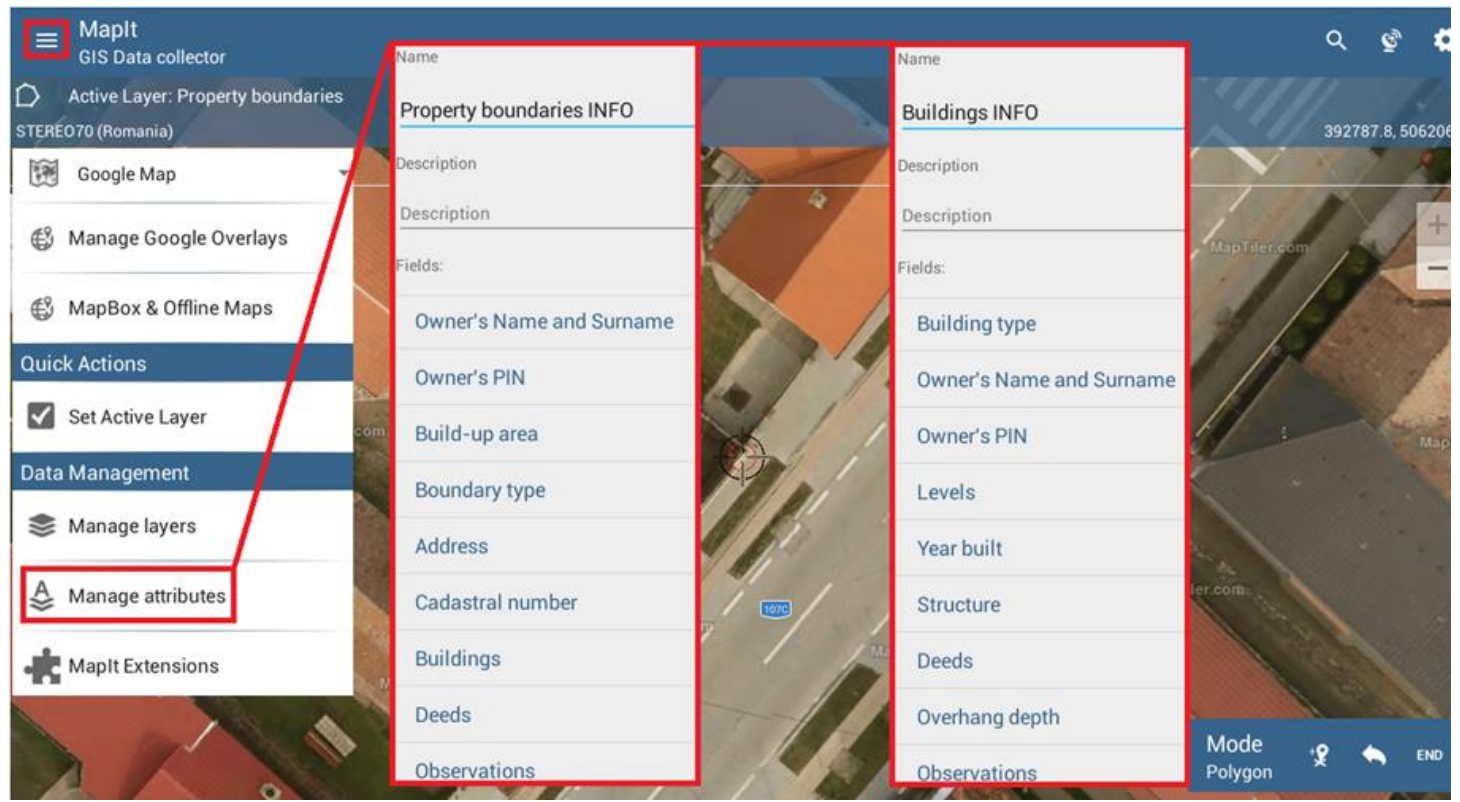

Figure 10. Managing attributes in MapIT application.

In the field, the right holder used his/her tablet that had the MapIT application installed and with its assistance, he/she had to realize an approximate digitization of the properties and buildings boundaries. These boundaries were extracted from the orthophoto, which has a pixel dimension of $5 \mathrm{~cm}$. Later, the extracted boundaries were rectified at the office and the precise property boundaries and buildings footprint identification were determined.

The cadastral data referring to the property owner, deeds and relevant collected information about the selected entity/ property were collected in the same time with the boundary digitization (Figure 11), as well as a photo of the digitized property (Figure 12).

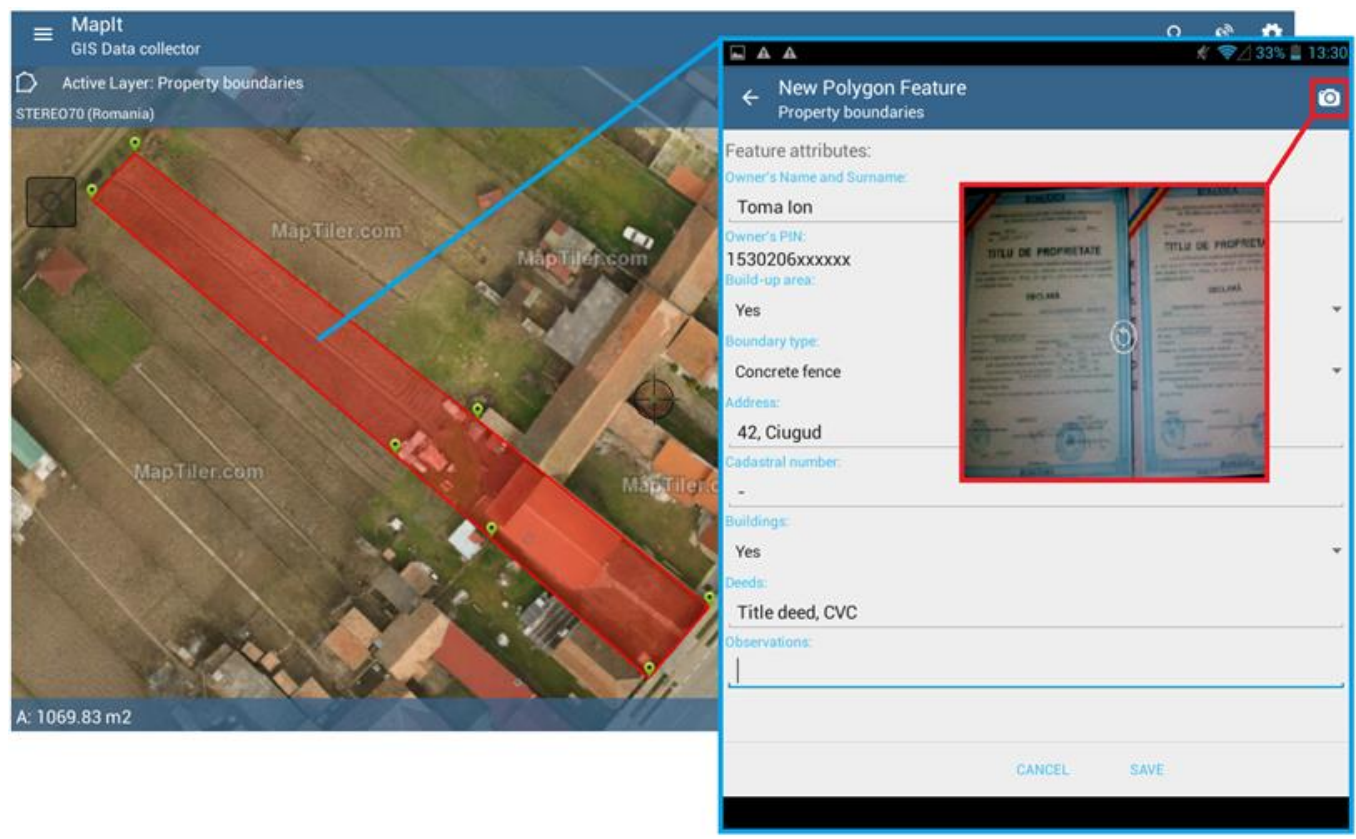

Figure 11. Map IT's interface for property boundaries data collection - uploading property's deed. 


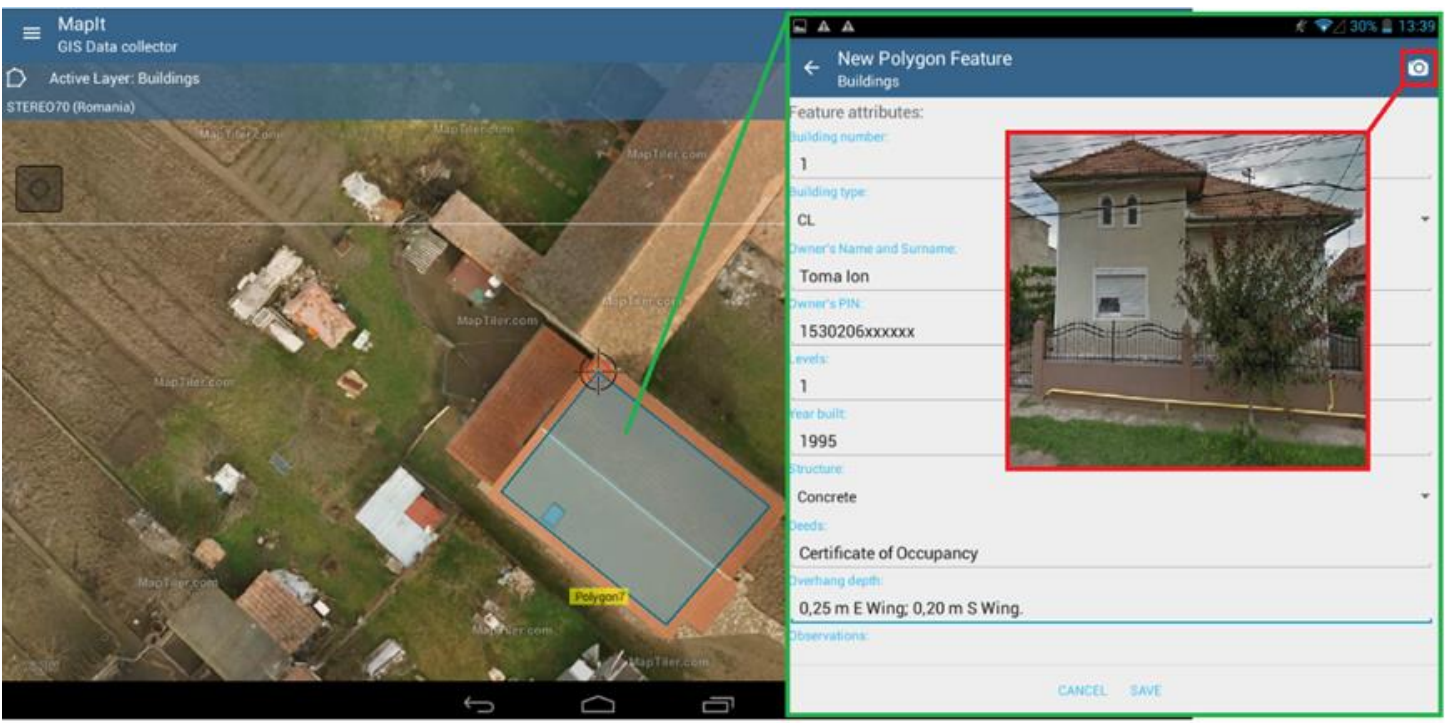

Figure 12. Map IT's interface for property boundaries data collection - uploading a photo of the property.

For better building footprint determination at the office, the right holder/ property owner measured the overhang depth in the field. For this case study, the building's perimeter had also been measured by a surveyor using a laser telemeter. After the data acquisition process, the polygons that define the property boundaries and those who define the buildings were exported in shapefile format files.

The areas, which cannot be determined (around 12\%), were measured using GNSS systems and/or total station by a surveyor as well.

For the optimization of the building footprint determination process the point cloud which resulted by image pixel correlation has been used to determine the overhang depth $(70 \mathrm{~cm})$ (Figure 13).

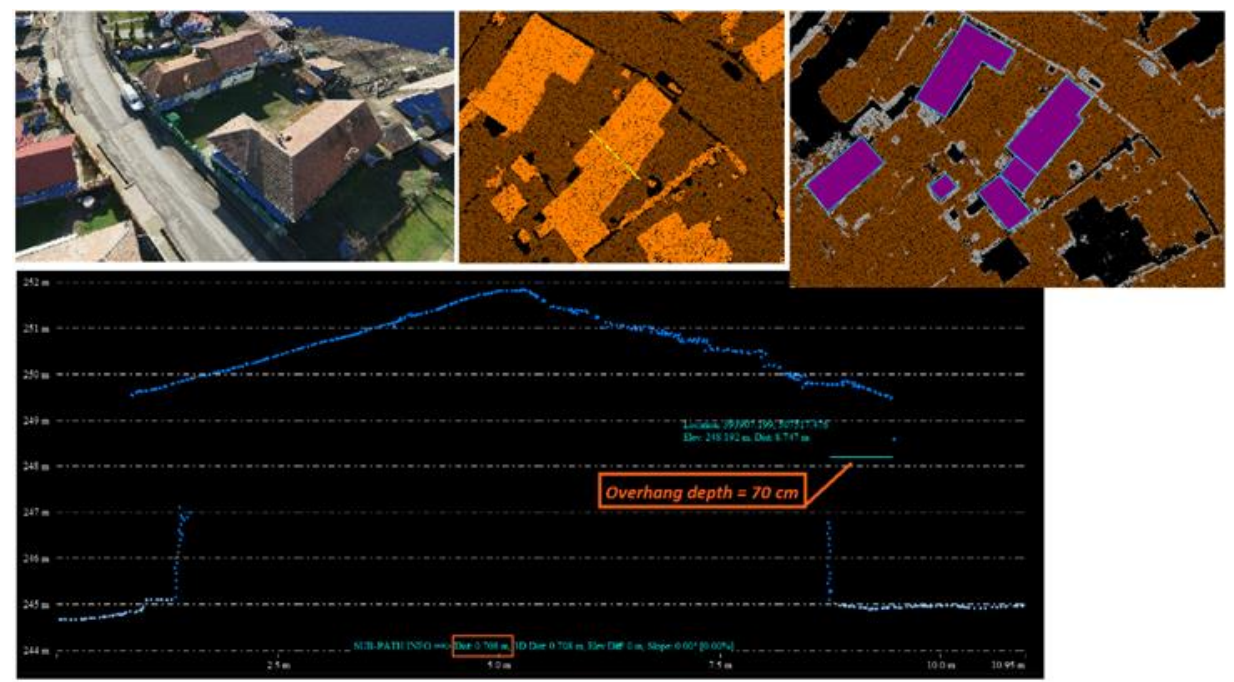

Figure 13. Building footprint determination using the correlated point cloud.

The crowdsourced cadastral data for the urban area (Caracal city center) (Figure 14a) was collected in $25 \mathrm{~h}$ (three days) by two teams of volunteers/ property owners and consist of 428 polygons that contain property boundaries information and 1460 polygons that contains buildings information. 

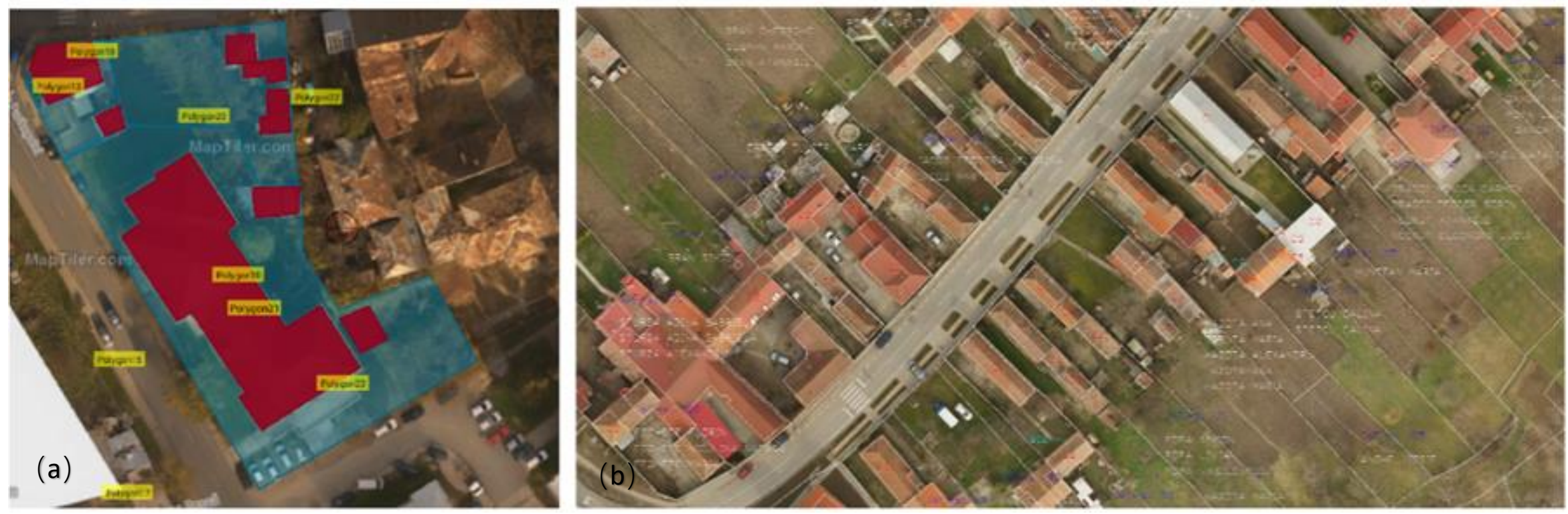

Figure 14. Crowdsourced cadastral data. (a) Caracal city center and (b) Ciugud village build-up area. 
The crowdsourced cadastral data for the rural area (Ciugud village build-up area) (Figure 14b) was acquired in nine hours by two teams of volunteers/ property owners and consist of 156 polygons that contain property boundaries information and 520 polygons that contains buildings information.

Following the completion of the field procedures, a 5-days campaign of classical survey measurements was realized in both areas, in order to verify the correctness of the acquired crowdsourced data. The measurements were realized with the Leica TS 02 total station. The comparison of the two datasets presents that the crowdsourced cadastral data set are within the official accuracy for the cadastral surveying according to the Romanian NCMA's specifications (RMSxy for urban areas is 0.4 and the RMSxy for the non-build-up areas is $1.0 \mathrm{~m}$ ) (Figure 15).

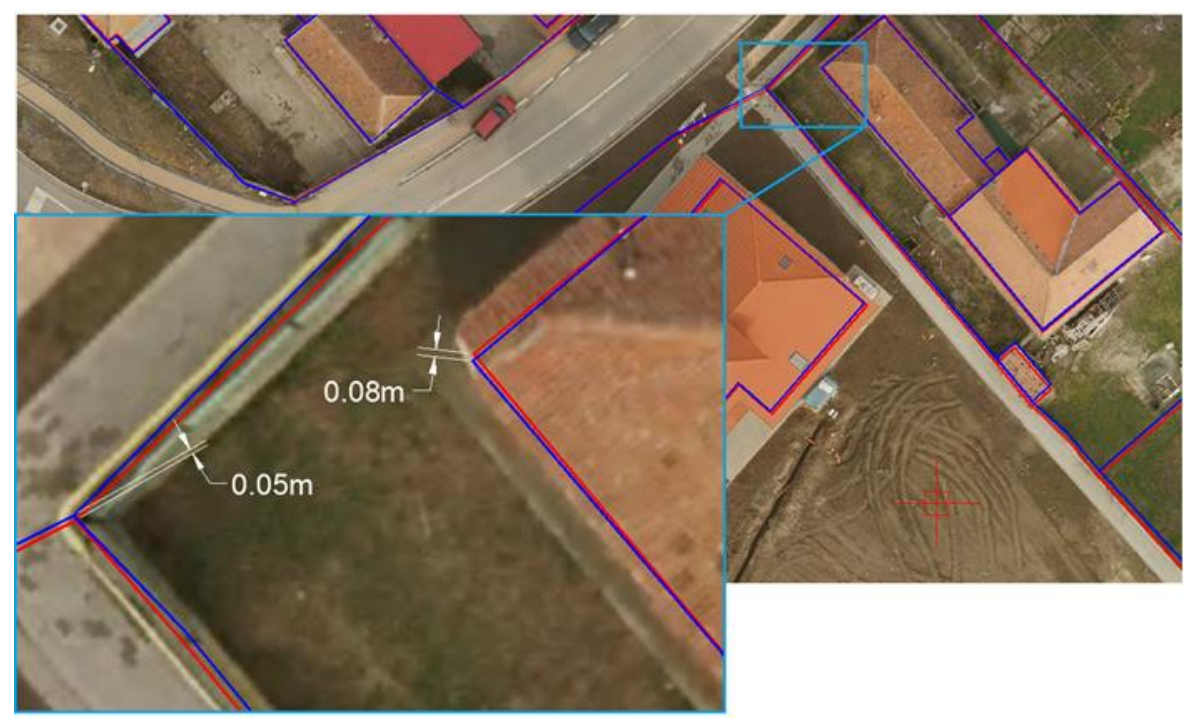

Figure 15. Comparison of the recorded boundaries using the proposed procedure (in blue) with those obtained from the official Cadastral Maps.

\section{Discussion and Conclusions}

The purpose of the proposed fit-for-purpose procedure described above is to facilitate the development of an accurate, assured, and authoritative cadastre using web services and crowdsourcing technique in a more affordable and reliable way to speed up the completion of a national cadastre at a country wide scale with increased participation of owners in the data collection process. Essentially, the aim is to facilitate the participation of right-holders and the local residents in the adjudication of property rights and cadastral data acquisition.

The community involvement can be improved through various stages and can be based in a series of main lessons, technical aspects and successful factors that can be adopted by the proposed procedure that was introduced in 2016 by Basiouka and Potsiou [10].

The elements affecting the geometric accuracy, quality and completion of the proposed procedure are:

(a) the quality and accuracy of the used basemap: this depends on the funding sustainability of each project and what they can afford; the used basemap may vary from aerial photo, OpenStreetMap, googlemap, orthophoto, very large scale orthophoto, etc.). The optional usage of opensource applications such as the MapIT (instead of commercial apps) with a good quality orthophoto as a basemap gives equally fast and good results.

The case studies have proved that the achieved geometric accuracies using accurate orthophotos and crowdsourcing may well satisfy the technical specifications for a AAA cadaster. Validation of the geometric accuracy should be made by the NMCA upon receipt, prior to the publishing of the draft cadastral maps and the call for objections. A quality control study should check the parcel boundary 
coordinates accuracy sporadically. Validation of the submitted legal documents is also necessary in order to compile a AAA cadastre. If validation is not affordable, this step may be postponed and the draft cadastral maps may be used for other governance purposes but not for supporting a functioning real estate market and investment on land; an alternative solution would be the adoption of an "open cadastre" where validation procedure may be facilitated to a great extent by the community while the remaining conflicting cases should again be validated by the experts. This issue still needs to be more investigated though.

(b) the user's ability to identify the parcel boundary points on the basemap (if not, he/she should visit the parcel and the help of the mobile phone GNSS for rough navigation but also refine the measurement by moving the cursor manually). Another option is to have the help of a team leader;

(c) the complexity of the site: built and natural environment (this affects the surveying method to be used e.g., crowdsourcing, photogrammetric, field-survey, or a combination);

(d) the type of vegetation that may hide boundary points on the basemap (orthophoto) mainly in the rural areas or high buildings that may hide parts of land parcels in urban areas. For that reasons a field completion of the cadastral maps may be needed in some areas; an application is published by the authors [31] and

(e) the participation of right holders and their digital skills. Digital skills may not be a big issue as a volunteer young student, or team leader, etc. may provide support, or even a neighbor or a professional.

New IT tools are introduced for the compilation of the cadastral surveys, supported by crowdsourcing techniques and m-government services. Citizens should be able to use both Internet and mobile devices, such as smart phones, for the cadastral registration procedure. User friendly Web and mobile applications need to be created by the NCMAs in order to collect the necessary information. Demonstration videos and detailed instructions for the usage of both of the applications will be provided by the NCMAs.

The biggest challenge is that people will recognize the value of the project and be aware of the benefits. Experience from earlier research in Greece shows that the right holders were seriously disappointed due to the long delays in the compilation of the formal cadastral surveys and the gross errors in the draft cadastral maps in the rural areas that they were willing to participate and solve the problem. That way they could save extra expenses and time and they could unblock the market as during the delays no transaction could be allowed. International experience has shown that this kind of FFP methods can speed up the cadastral registration times and reduce costs (e.g., a recent case study in Colombia presented that the nationwide land administration of the country will be completed within seven years: two years of preparation and piloting and five years for data collection) [30]. However, registration fees as well as other relevant policies such as annual property taxation should be carefully planned so that right holders will not be discouraged and unwilling to participate and declare their rights. The crowdsourced 2D cadastral survey model, which is proposed, supports a new form of relationship between professionals and citizens. Cooperation with citizens enables new roles for the surveyors who are responsible for the training of volunteers and the evaluation of data collected by the crowd.

Finally, it may be concluded that research in developing a F-F-P methodology for the compilation of AAA cadastral surveys and for introducing increased community (right holders/local people/team leaders, etc.) participation for the compilation of AAA cadasters able to support the good governance of land and a smooth functioning of property markets has reach a good level of success. Technical and legal issues are addressed sufficiently, while legal validation procedure should be further investigated in order to be improved in terms of costs and time. Definitely for the success of the F-F-P methodology more research is still needed in improving the engagement of the crowd. Dedication, and long commitment of right holders and the community in general to participate and safeguard the success of the project is an issue that should be further investigated and improved; guidelines should be developed. 
Author Contributions: Conceptualization, Chryssy Potsiou, Charalabos Ioannidis and Konstantinos Apostolopoulos; Data Curation, Chryssy Potsiou, Cornel Paunescu, Konstantinos Apostolopoulos and Florin Nache; Formal analysis, Chryssy Potsiou, and Konstantinos Apostolopoulos; Investigation, Chryssy Potsiou, Konstantinos Apostolopoulos and Florin Nache; Methodology, Chryssy Potsiou, Konstantinos Apostolopoulos and Florin Nache; Project Administration, Chryssy Potsiou, Charalabos Ioannidis; Resources, Chryssy Potsiou, Konstantinos Apostolopoulos and Florin Nache; Software, Cornel Paunescu, Konstantinos Apostolopoulos and Florin Nache; Supervision, Chryssy Potsiou, Cornel Paunescu and Charalabos Ioannidis; Validation, Chryssy Potsiou, and Charalabos Ioannidis; Visualization, Chryssy Potsiou and Konstantinos Apostolopoulos; Writing-Original Draft Preparation, Konstantinos Apostolopoulos and Chryssy Potsiou; Writing-Review \& Editing, Chryssy Potsiou. All authors have read and agreed to the published version of the manuscript.

Funding: This research received no external funding.

Acknowledgments: The contribution of Konstantinos Apostolopoulos to this research is part of his PhD dissertation, which is supported by the Eugenides Foundation scholarship program.

Conflicts of Interest: The authors declare no conflict of interest.

\section{References}

1. United Nations. Transforming our World: The 2030 Agenda for Sustainable Development. 2015. Available online: https://sustainabledevelopment.un.org/content/documents/21252030\%20Agenda\%20for\% 20Sustainable\%20Development\%20web.pdf (accessed on 1 October 2019).

2. Torhonen, M.; Salzmann, M.; Kasperavicius, R.; Sas, E.; Hokkanen, J.; Rokos, D. Sustainabl Governance of European Cadastre and Land Registry Agencies. In Proceedings of the World Bank Conference, Washington, DC, USA, 23-27 March 2015.

3. Avgerinou-Panagiotou, A.; Zifou, M.; Lamprou, A.; Papakyriakopoulos, G.; Lawrence, V.; Schonegevel, J. Understanding Business Planning for the Modernization of a Land Registration System. In Proceedings of the World Bank Conference, Washington, DC, USA, 19-23 March 2018.

4. Lamprou, A.; Lawrence, V.; Papakyriakopoulos, G.; Schonegevel, J. Drawing on Best Practice to Assess the Geomaturity of a Country's NSDI Using a Recent Example of the Work Undertaken in Greece. In Proceedings of the World Bank Conference, Washington, DC, USA, 19-23 March 2018.

5. Lawrence, V.; Zifou, M.; Lamprou, A.; Papakyriakopoulos, G.; Avgerinou-Panagiotou, A.; Stokes, J.; Schonegevel, J. Understanding the 'People Issues' of Organisationally Modernising a Land Registration System. In Proceedings of the World Bank Conference, Washington, DC, USA, 19-23 March 2018.

6. Papakyriakopoulos, G.; Lawrence, V.; Zifou, M.; Lamprou, A.; Avgerinou-Panagiotou, A.; Stokes, J.; Schonegevel, J. A Model for Modernizing the Organization of Land Registration Systems. In Proceedings of the World Bank Conference, Washington, DC, USA, 19-23 March 2018.

7. Zifou, M.; Lamprou, A.; Papakyriakopoulos, G.; Avgerinou-Panagiotou, A.; Lawrence, V.; Schonegevel, J. Creating a Strategy for the Organisational Modernisation of A Land Registration System. In Proceedings of the World Bank Conference, Washington, DC, USA, 19-23 March 2018.

8. Williamson, I.; Rajabifard, A.; Kalantari, M.; Wallace, J. AAA Land Information: Accurate, Assured and Authoritative. In Proceedings of the 8th FIG Regional Conference 2012 on "Surveying towards Sustainable Development", Montevideo, Uruguay, 26-29 November 2012.

9. Basiouka, S.; Potsiou, C. The volunteered geographic information in cadastre: perspectives and citizens' motivations over potential participation in mapping. GeoJournal 2014, 79, 343-355. [CrossRef]

10. Basiouka, S.; Potsiou, C. A Proposed Crowdsourcing Cadastral Model: Taking Advantage of Previous Experience and Innovative Techniques. In European Handbook of Crowdsourced Geographic Information; Capineri, C., Haklay, M., Huang, H., Antoniou, V., Kettunen, J., Ostermann, F., Purves, R., Eds.; Ubiquity Press: London, UK, 2016; pp. 419-433.

11. Mourafetis, G.; Apostolopoulos, K.; Potsiou, C.; Ioannidis, C. Enhancing cadastral surveys by facilitating the participation of owners. Surv. Rev. 2015, 47, 316-324. [CrossRef]

12. Apostolopoulos, K.; Geli, M.; Petrelli, P.; Potsiou, C.; Ioannidis, C. A new model for cadastral surveying using crowdsourcing. Surv. Rev. 2018, 50, 122-133. [CrossRef]

13. Government Gazette. Law 2308/1995. Athens. Greece. (available in Greek). Available online: https: //www.ktimatologio.gr/photo/medium/201912/ag8saf1575906430338.pdf (accessed on 1 October 2019). 
14. Government Gazette. Law 3481/2006. Athens. Greece. (available in Greek). Available online: https: //okxediavouleusi.files.wordpress.com/2012/08/all-related-pdfn.pdf (accessed on 1 October 2019).

15. Austrian Cultural Heritage, 200 years Cadastre-The Cadastral System in Romania. 2017. Available online: http://www.bev.gv.at/pls/portal/docs/PAGE/BEV_PORTAL_CONTENT_ALLGEMEIN/0200_PRODUKTE/ PDF/FESTSCHRIFT_200_JAHRE_KATASTER.PDF (accessed on 1 October 2019).

16. Government Gazette. Law 7/1996. Available online: http://www.ancpi.ro/files/Documente/Lege_7_1996.pdf (accessed on 1 October 2019).

17. United Nations. The millennium Development Goals Report 2014. Available online: http://www.un.org/en/ development/desa/publications/mdg-report-2014.html (accessed on 1 October 2019).

18. United Nations. Open Working Group Proposal for Sustainable Development Goals. 2014. Available online: https://sustainabledevelopment.un.org/index.php?page=view\&type $=400 \& n r=1579 \&$ menu $=130$ (accessed on 1 October 2019).

19. De Zeeuw, K.; Salzmann, M. Tenure Security as a Service. FIG Working Week 2017, Helsinki, Finland. Available online: https://www.fig.net/resources/proceedings/fig_proceedings/fig2017/papers/ts08a/TS08A_ zeeuw_salzmann_8976_abs.pdf (accessed on 1 October 2019).

20. Making FFP Land Administration Compelling and Work in Practice. Available online: http://www.fig.net/ resources/monthly_articles/2018/enemark_mclaren_october_2018.asp (accessed on 1 October 2019).

21. Ambani, S.; Kalinga, J.; Lemmen, C. Handheld Land Administration Mapping Methods: Institution of Surveyors of Kenya demonstrates alternative approaches. GIM Int. 2017, 31, 25-27.

22. Lengoiboni, M.; Lemmen, C.; Zevenbergen, J. Innovative Tools for Tenure Recordation: Documentation of Overlapping and Secondary Land Rights. GIM Int. 2017, 31, 41-43.

23. Crowd Sourcing for Land Administration: Perceptions within Netherlands Kadaster. Available online: http://www. fig.net/resources/proceedings/fig_proceedings/fig2012/papers/ts03b/TS03B_keenja_devries_et_al_5611.pdf (accessed on 1 October 2019).

24. Ensuring the Rapid Response to Change, Ensuring the Surveyor of Tomorrow. FIG Article of the Month: April 2015. Available online: http://www.fig.net/resources/monthly_articles/2015/potsiou_april_2015.asp. (accessed on 1 October 2019).

25. FIT-FOR-PURPOSE LAND ADMINISTRATION Guiding Principles for Country Implementation. Available online: https://www.fig.net/news/news_2016/2016_07_gltnguide/fit-for-purpose-land-admguiding-principles-for-country-implementation.pdf (accessed on 1 October 2019).

26. Potsiou, C.; Volakakis, M.; Doublidis, P. Hellenic cadastre: state of the art experience, proposals and future strategies. Comput. Environ. Urban Syst. 2001, 25, 445-476. [CrossRef]

27. Rokos, D. Recent developments in the context of the Hellenic Cadastre. In Proceedings of the Tufe2018 Economy, Society and Climate Change - The impact of mega trends in the Built Environment, Construction Industry and Real Estate, Athens, Greece, 7-10 November 2018.

28. Savoiu, C.; Lemmen, C.; Saviou, I. Systematic Registration in Romania a New Opportunity for Land Consolidation. FIG Working Week 2015, Sofia, Bulgaria. Available online: https:/www.fig.net/ resources/proceedings/fig_proceedings/fig2015/papers/ts01c/TS01C_savoiu_savoiu_et_al_7749.pdf (accessed on 1 October 2019).

29. Grecea, C.; Rusu, G.; Muşat, C.C.; Moscovici, A.M. Challenges in implementing the systematic land registration in Romania. In Proceedings of the 1st European Conference of Geodesy and Geomatics Engineering, Antalya, Turkey, 8-10 October 2013.

30. Molendijk, M.; Dukon, T.; Lemmen, C.; Morales, J.; Endo, V.; Rodriguez, S.; Dueñas, J.; Sanchez, I.; Spijkers, P.; Unger, E.; et al. Land and Peace in Colombia: FFP Methodology for Field Data Collection and Data Handling. In Proceedings of the World Bank Land and Poverty Conference 2018, Washington, DC, USA, 19-23 March 2018.

31. Gkeli, M.; Apostolopoulos, K.; Mourafetis, G.; Ioannidis, C.; Potsiou, C. Crowdsourcing and mobile services for a fit-for-purpose Cadastre in Greece. In Proceedings of the Fourth International Conference on Remote Sensing and Geoinformation of the Environment (RSCy2016), Paphos, Cyprus, 4-8 April 2016.

32. Environmental Systems Research Institute (ESRI). ArcGIS Online Application. Available online: http: //www.esri.com/software/arcgis/arcgisonline (accessed on 10 September 2017).

33. Amhar, F.; Jansa, J.; Ries, C. The Generation of the True Orthophotos Using a 3D Building Model in Conjunction with a Conventional DTM. Int. Arch. Photogramm. Remote Sens. 1998, 32, 16-22. 
34. Nache, F.; Stănescu, R.A.; Păunescu, C. The processing workflow needed in order to obtain the main photogrammetric products used in cadaster and topography. In Proceedings of the National Technical-Scientific Conference (Modern Technologies for the 3rd Millennium, Oradea, Romania, 23-24 March 2017.

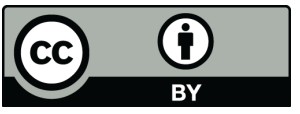

(C) 2020 by the authors. Licensee MDPI, Basel, Switzerland. This article is an open access article distributed under the terms and conditions of the Creative Commons Attribution (CC BY) license (http://creativecommons.org/licenses/by/4.0/). 